\title{
Electrical Engineering Graduate Studies Program of the California Institute of Technology
}

\author{
R O Y A L W. S O R E N S E N \\ FELLOW AIEE
}

$\mathrm{G}^{\mathrm{R}}$ RADUATE studies for Tectrical engineering students at the California Institute of Technology are primarily studies leading to the degree of doctor of philosophy in electrical engineering, with a somewhat lesser emphasis upon the professional degree, electrical engineer. Aeronautical, civil, and mechanical engineering graduate studies follow about the same pattern, with more professional degrees granted in those courses than in electrical engineering.

The arrangement of the courses of study, the standards of scholarship, and the admission requirements for all graduate students in all departments are administered by a committee on graduate studies which also selects all students admitted to the college to study for the master's degree. All programs of study and admission to candidacy for the engineering master's degree are in charge of the committee on courses in engineering which passes upon the rights of study continuation and makes recommendations for or against graduation for all engineering students studying for bachelor's or master's degrees.

As it is the common practice of the institute to admit students seeking their first admission to graduate studies to studies leading to the master's degree, this plan works well in several ways. It provides for a good plan of transition from undergraduate to true graduate status, and affords a way to add that much desired fifth year to the engineering curricula without depriving engineering students of the bachelor of science degree for the completion of 4-year courses, or subjecting them to the experience of receiving second bachelor's degrees for the completion of 5-year courses. The plan permits the faculty to have contact for a year with the students who wish to do advanced graduate work before having to pass upon their abilities to carry on regular graduate studies programs. All students who have obtained any degree at the institute must make application for admission to study for any other degree and must be considered as students enrolling for the first time.

Essential substance of a conference paper presented at the AIEE summer general meeting, Montreal, Quebec, Canada, June 9-13, 1947.

Royal W. Sorensen is professor of electrical engineering, California Institute of Technology, Pasadena.
The fifth year courses are taught in much the same manner as the junior and senior courses. At least 20 per cent of all fifth year curricula, like those of the preceding four years, must be selected humanities. There are a number of these courses from which the students may choose. For an electrical engineering student, one half the fifth year curriculum chosen will be prescribed electrical engineering subject matter (Table I). For the normal student, the remaining portion (between one fourth and one third of the total) will be approved electives. These may be mathematics, engineering, or science courses. This plan of granting the master of science degree without a thesis is not approved by all educators, but observation of the performanceafter graduation of the men who have masterof science degrees provides convincing evidence that the lack of a thesis has not resulted in degree holders who are not entitled to a degree. The plan does not preclude earning a master of science degree via the thesis route when qualified students have in mind a worthwhile project that will produce a suitable thesis.

The California Institute of Technology graduate studies pattern, though its true graduate work applies only to work for the higher degrees, cannot be discussed without some consideration of not only the fifth year studies, but also the bachelor's degree studies. The declared policy of the school is that it is a college incorporating the strongest possible research program, rather than a research institute with an educational department. Faculty members quite often simultaneously or interchangeably teach graduate and undergraduate courses and also carry on research. Graduate students holding graduate assistantships teach undergraduate and fifth year students, very often with a proficiency not always equaled by regular faculty members. Fifth year engineering students and students working for the engineering and doctorate degrees arrange curricula well interwoven with the curricula of students majoring in science. Indeed, the undergraduate curricula for applied physics students and electrical engineering students have much in common throughout the four undergraduate years. Furthermore, the electrical, mechanical, and aeronautical students have identical courses through 
the junior year (see Table II), and the civil engineering students have done about all of that common work by graduation.

\section{DOCTORATE DEGREE REQUIREMENTS}

The general requirements which must be met by students working for doctorate degrees include

1. Breadth of scientific attainment.

2. Power to investigate scientific problems independently and efficiently.

3. Research and thesis.

4. Satisfactory grades in systematic studies of advanced character in science and engineering preceded by certain specific courses.

5. Power of oral and written expression.

6. Reading knowledge of two foreign. languages; German, French, or Russian.

7. Minimum graduate residence of three years with at least the last one at the institute.

Specific Courses for Doctor's Degree in Electrical Engineering. To be recommended for candidacy for the doctor's degree in electrical engineering, the applicant must pass the following subjects with a grade of $C$ or better:

Electricity and magnetism (27 units)

Engineering mathematical physics (45 units)

and one of the following subjects:

Analytical mechanics (36 units)

Applied mechanics (48 units)

and one of the following subjects:

Introduction to mathematical physics (36 units- $\mathrm{Ph} 5$ )

Introduction to mathematical physics (45 units- $\mathrm{Ph} 6$ )

Engineering mathematics (27 units)

Methods of advanced calculus (10 units)

Differential equations (10 units)

and 30 units from the following:

Advanced electric power system analysis (36 units)

Dielectrics (6 units)

Circuit analysis (27 units)

Electromagnetic fields (27 units)

When the student has completed those requirements and has been admitted to candidacy, he should

1. Show ability to solve almost any problem relating to electrostatics or steady current flow in extended media involving purely conducting or purely insulating boundaries in the rectangular, cylindrical, spherical, or spheroidal co-ordinate systems.

2. Be able to devise conformal transformation for 2-dimensional problems that will solve most problems involving rectangular boundaries and right angle bends, such as the increase in resistance and distribution of local heating due to a crack in a bus bar, or the increase in a multiplate parallel plate capacitor due to variations in the field near the edges.

3. Know how to solve eddy current problems with simple geometrical boundaries as, for example, the forces acting on a magnet moving near a conducting sheet or the effect on the self-inductance and resistance of coils placed in shielding metallic cans, and determine the strength and distribution of the external fields.

4. Be familiar with the solutions of Maxwell's equations in all the common co-ordinate systems and with their applications to transmission lines, antennas, wave guides, and cavities.

5. Be able to attack intelligently problems involving these equations for which there are no answers in the handbooks.

6. Be able to use general theorems, such as those of Gauss and Green, to transform unfamiliar problems into familiar ones.

"Electricity and magnetism," a 9-hour-per-week course for one college year, is the crucial course for developing and testing the student's qualifications for attaining the specified abilities. "Engineering mathematical physics," a 12-hour-per-week throughout-theyear course, is provided to open the way to apply the techniques learned in "electricity and magnetism" and preceding courses to practical engineering problems.

Time Required. The minimum required college residence time for the doctorate degree is three years subsequent to receipt of the baccalaureate degree, with a minimum of one year of residence at the institute. So far the minimum residence of any student at the institute who has obtained the doctorate degree has been two years.

Degrees Granted. The institute granted its first doctorate degree, in physics, to an electrical engineering student in 1924. This was followed by a second similar degree in 1926, but since that time the doctor of philosophy degree in electrical engineering has been awarded. The recipients of these degrees quite frequently have been men who, as undergraduates, majored in physics. Also, undergraduate electrical engineering majors have obtained physics doctorates.

Present Postwar Enrollment. For the 1946-47 year, 50 students have been enrolled for studies leading to the master's degree, most of whom will obtain the degree with one year of residence. An equal number is admitted for 1947-48. Thirteen of the present 50 obtained the bachelor's degree at the institute, and two of the six electrical students now enrolled for work beyond the fifth year obtained degrees at the institute. Thirteen of the present 50 fifth year students have been admitted to studies leading to the doctorate degree. This number, though larger than for any preceding year, is still about one fourth of the fifth year group, which is the same fraction of the fifth year group as continued for doctorate work before World War II.

Standard Criteria for the Student. Great care has been taken to admit for doctorate studies only students with high analytical ability and/or extraordinary experimental technique, and who show promise of making real contributions to the profession rather than just doing a large amount of standard engineering well. The number admitted is limited to the few that the staff can supervise carefully. This procedure does much to guarantee that an electrical engineering doctorate will be a man well enough acquainted with physics and mathematics to feel at home in the company of specialists in those fields.

The Thesis. The doctorate thesis is, of course, the im- 
portant part of any doctorate degree achievement. The electrical theses to date have covered a wide range of subjects and the majority of them have been developed experimentally. A few theses, mostly by students from countries other than the United States, have been entirely analytical, however. Some of the theses researches would be very acceptable as physics doctorate theses. The electrical features of these theses concern the instrumentation involved in the researches.

Theses researches are carried on during the summer quarter as well as during the college terms. The institute normally does not hold summer classes but the faculty operates on a yearly basis, conducting its own researches and aiding the students in their work. No tuition charge is made for summer use of laboratories but full credit is allowed for research during that time.

Professional Degree Requirements. The professional degree requirements are as rigorous with respect to quality as those of the doctorate degree. The difference is the minimum graduate residence time requirement of two years for the former as compared with the 3-year doctorate requirement, and a reduction of the amount of advanced physics courses required. The specific requirements are those listed for the doctorate degree with the physics courses, "electricity and magnetism," omitted.

Every possible effort is made to prevent the professional degree from becoming a degree granted to students who try for a doctorate degree and fail. In general, students are not encouraged to enroll for the professional degree in electrical engineering, but the other engineering divisions, particularly the aeronautics group, find the professional degree very useful and grant a considerable number.

Research Facilities. Students engaged in research are given access at all times to facilities required for their work. These are not only good laboratories and libraries, but also well-equipped student shops where students may construct equipment for which their technique qualifies them, as well as shops manned by skilled mechanics for construction requiring more skill than possessed by students.

The special research facilities for electrical engineers at the institute include the high-voltage laboratory, the analogue computer laboratory, and the electronics laboratories. These laboratories are not isolated either by location or organization, but are closely related and interoperative with the other engineering and science laboratories. For example, some of the electrical student research rooms are in the building that houses the nuclear physics group. The electronics and analogue computer laboratories are in the physics laboratory buildings and are surrounded by research rooms occupied by physicists engaged in their particular type of researches. The physicists often use the high-voltage laboratory. The civil and mechanical engineers have used some of its equipment. A number of electrical engineering graduate students are engaged in researches where their training and interest makes them valuable in developing electrical means for measuring phenomena encountered in aerodynamic, hydrodynamic, and mechanics problems.

Laboratories and shop facilities, no matter how perfect, do not guarantee high quality graduate courses and research programs. Their quality is determined by the personnel of the faculty. The institute has been fortunate in that respect. Its policy was initiated in 1908 when the late Doctor George Ellery Hale joined the board of trustees of Throop College of Technology with the provision that the trustees change its operation as a technical institute to that of an engineering college similar to the Massachusetts Institute of Technology. However, he suggested two points of difference: a large portion of humanities in the curricula, and a stronger emphasis on the basic sciences than was included in the engineering curricula of most colleges and universtities.

The Engineering Doctorate and Industry. For several years industry seemed in doubt as to the value of the engineering doctorate degree even though its research staffs were made up largely of science doctorates. This doubt was expressed by the lack of a willingness on the part of industry to make the starting pay for engineering doctorates larger than for men with the bachelor's degree only. Or if it were made larger, the increment above the bachelor's pay was very small. The Bell Telephone Laboratories organization was a notable exception and thereby obtained some very valuable men. Since about 1934, however, the attitude of industry has changed, and quite generally recommended doctorates find their starting salaries about 50 per cent greater than that of the holders of bachelor's degrees. Indeed, at the beginning of this change of opinion, one representative of a large employer of college graduates expressed publicly high regard for California Institute of Technology engineering doctorates and made an apology for having underrated the value of engineering doctorate training. A continuation of that high regard is something to be maintained zealously. As the regard is based upon the performance of engineers who have included much work in mathematics and physics in their doctorate programs, care must be exercised to continue doctorate programs that do not revert to so much engineering as to cause a reduction in the amount of science and mathematics students may study.

The reluctance of industry to agree with the institute on the doctorate degree value in those earlier years is quite understandable. Some engineering doctorates who were employed were found less qualified than many bachelors for the work to be done. Under such conditions management of course had to make embarrassing adjustments. Improper doctorate standards, or failure on the part of industry and college to agree as to 
Table I. Fifth Year Engineering Curriculum

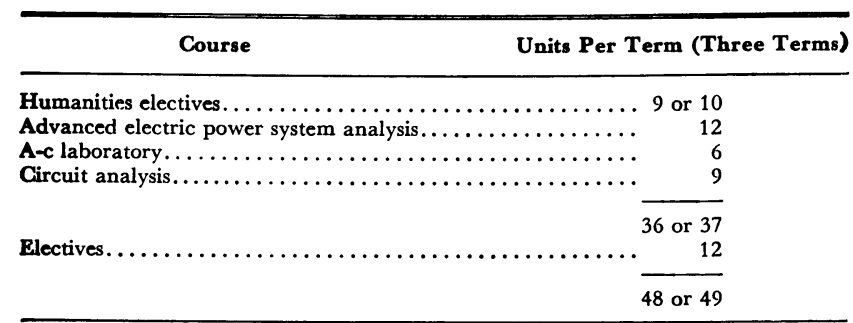

what may be expected of the doctorate educational program, bring about such conditions.

Engineering Education Postwar II. Engineers and scientists as a result of the war have attained public acclaim and much long desired professional recognition. Indeed the swing of public sentiment almost has overshot a good balance. To avoid a swing to low repute, great planning care is required. The present problem is very complex. Some of the factors to be considered are $20^{\circ} 8 \backslash_{10}$

1. The men who made early electrical engineering were not educated in engineering colleges. They were men trained in science or in the "school of hard knocks."

2. The men who made 20th century engineering have been largely the product of engineering colleges. They have been taught manual dexterity, the use of simple mathematics and elementary physics in solving not very complicated engineering problems, and the use of handbooks written by leaders in the profession.

3. The world wants more engineering so there is, at present, an apparent shortage of engineers. At the same time, the walls of engineering colleges figuratively are bursting because of the large number of students, while outside the walls a larger number is trying to get in.

4. Many are inclined to think that there is magic in taking graduate work, and far too great a share of them think graduate work means more work similar to the undergraduate work.

5. There is much equipment for laboratories available at little or no cost.

6. There is a great shortage of experienced teachers of electrical engineering, particularly teachers with a background of experience plus advanced training in physics and mathematics.

In trying to account for all these factors, one should not forget that large laboratories do not guarantee valuable research programs. The California Institute of Technology program grew around men and not laboratories. The men conceived the lines of research to be followed and, in most instances, from humble and limited beginnings acquired laboratories. The pressure for graduate work should not lower the tone that has gained respect for that work.

The emphasis that has been placed upon mathematics, basic science, and humanities obviously reduces the college time that may be devoted to engineering studies unless the residence time is increased. How long that residence may be profitable must be determined by each individual. Some of the determining parameters are the student's age, his ability to continue his interest in college life, and his financial status. The average graduate residence of the institute electrical engineering doctorates has been about four years.

The average age of engineering doctorate under 30 is about 26.3 years. This probably will increase a bit until the effect of the war is over. In general, it seems highly desirable for men to attain their doctorate degree before they are 30 years old. If they are in the upper 20's they should have had, prior to the receipt of the doctorate degree, some practical engineering experience.

This article should not be construed as criticizing in any way the excellent education program conducted by the colleges up to the present time. Colleges have met the demands of industry well, but these demands probably have forced an overemphasis on the manufacturing, design, and operation techniques of apparatus at the expense of a proper devotion to the fundamentals underlying those techniques. The fact that the techniques were developed around the scientific discoveries and laws pronounced by men like Faraday, Henry, Kirchoff, Maxwell, Steinmetz, and others, must not be overlooked. However, having gone through the required cycle of practical developments based upon the vistas these men opened with the resultant devices now available for our use, if we are to meet the engineering demands of the future we must return to a deeper study of the basic sciences. To do this well curricula must be rearranged to reduce the number of special courses and curricula options, and to teach the students to know that the basic courses are not pre-engineering courses to be passed and forgotten, but are a part of the profession of engineering. Indeed, one of my pet idiosyncrasies is that some day men will not be called civil, electrical, or mechanical engineers by virtue of words on a college diploma, but will be classified professionally by their occupation. Perhaps an anecdote will illustrate my meaning.

A former electrical engineering student, when an electrical engineering faculty member, happened upon several members of the mechanical engineering staff of the college where he taught. These professors were discussing a rather complicated thermodynamics problem and their lack of ability to solve it. The former student, always interested in anything involving mathematics, asked about the problem. The next day he

Table II. Third Year Engineering

Electrical, Mechanical, and Aeronautical Students

\begin{tabular}{|c|c|}
\hline Course & Units Per Term (Three Terms) \\
\hline $\begin{array}{l}\text { Introduction to literature....... } \\
\text { Applied mechanics (dynamics, } \\
\text { Basic electrical engineering.... } \\
\text { Basic electrical engineering lab } \\
\text { Engineering mathematics*..... } \\
\text { Thermodynamics and fluid mec }\end{array}$ & 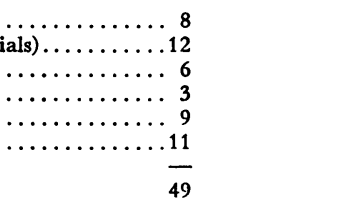 \\
\hline
\end{tabular}

* Students with scholastic records that warrant the excess load may take "introduction to mathematical physics" (12 units) as an alternate for "engineering mathematics." 
brought in a correct solution, whereupon one member of the group said, "I thought you were an electrical engineer, not a mechanical engineer." His answer was, "The logic in both fields is the same. The only difference is that the characters in the equations represent for the two fields different phenomena." When engineering education produces more students with that attitude, we no longer need worry about professional recognition.

Perhaps the ideas I have tried to convey in this article are provincial and too limited. My teaching experience all has been in one college. However, during World War II it fell to my lot to aid in assembling a group of men charged with producing new war equipment that involved pioneering in undeveloped engineering fields. When the problems were entirely new, particularly when they involved complicated analysis, the several groups seemed to show that men educated as physicists could solve these new problems more readily than men trained as engineers, and quite often could solve problems the engineers were unable to solve. If those impressions are indicative of the present engineering demands, our engineering education should not try to teach men about special devices but should provide for a thorough training in the basic sciences, citing typical engineering applications as much as possible. Such a program will place the burden of special engineering education upon industry where it belongs and where it should be done better than is possible in college. It is unreasonable to expect college professors to keep up with the many rapid industrial developments continually taking place.

In justice to engineers, we should not fail to note that a lot of the war work done by physicists would have been done with much less difficulty if the physicists, in turn, had been better acquainted with engineering practice.

\section{Electronic Stabilizer for Power Transmission}

\author{
ERNST F. W. ALEXANDERSON \\ FELLOW AIEE
}

\author{
D A V I D C. P R I N C E \\ FELLOW AIEE
}

$\mathrm{T}$

HE LIMITATIONS of conventional synchronous power transmission are well known. It has been pointed out that most long distance transmission lines operate at a load corresponding to surge impedance. ${ }^{1,2}$ This is the loading where the inductance and capacitance of the line neutralize each other so that the voltage remains constant throughout the line. Voltage regulation of an alternator historically has depended upon variation of the field current, and high-speed regulators have been developed in order to improve synchronous stability. This article describes a voltage control brought about by varying the output current. A reactive load is connected to the generator terminals. This load is varied electronically in such a way as to maintain the desired voltage and line current. Whereas regulation by field control is limited by the long time constant of the field winding, the electronic stabilizer acts upon the

Essentially full text of paper 47-162, presented at the AIEE summer general meeting, Montreal, Quebec, Canada, June 9-13, 1947, and scheduled for publication in AIEE TRANSACTIONS, volume 66, 1947.

Ernst F. W. Alexanderson is consulting engineer and David C. Prince is vicepresident in charge of electrical engineering department, General Electric Company, Schenectady, N. Y. transient reactance and therefore it has the fast response needed to increase the stability of long transmission lines.

In its function it is analogous to a synchronous condenser because it is used to regulate the voltage at the point where it is connected by drawing a controllable current from the line.

\section{ANALYSIS}

With fixed excitation the conditions for stability limit are shown in Figure 1. As the load motor (or equivalent) pole axis lags behind the generator pole axis by the angle $\theta$, the vector difference $\boldsymbol{E}_{D}$ of effective voltages follows a circular locus. The current follows a similar locus. Neglecting circuit resistance, current $I$ has the greatest projection on voltage $\boldsymbol{E}_{\sigma}$ when $\theta=90$ degrees. For greater angular lag, restoring torque as measured by $\boldsymbol{E}_{\boldsymbol{\theta}} \boldsymbol{I} \cos \theta / 2$ is less and the load falls out of step.

Corresponding to this condition, the difference voltage may be considered as divided into fractions, $0-1$ the drop corresponding to the generator armature reaction, 1-2 the drop across the generator transient impedance, 2-3 line drop, 3-4 load transient impedance, 4-5 load armature reaction. Quantities $E_{2}$ and $E_{3}$ are the voltages actually seen by voltage measuring devices at the 